\title{
High expression of microRNA-500 is associated with poor prognosis in patients with acute myeloid leukemia receiving allogeneic hematopoietic stem cell transplantation
}

\author{
GAOQI ZHANG ${ }^{1}$, JINLONG SHI $^{2,3}$, XINRUI YANG ${ }^{1}$, XINPEI ZHANG ${ }^{1}$, LINGXIU ZHANG $^{4}$, \\ JILEI ZHANG ${ }^{1}$, SIYUAN YANG ${ }^{1}$, JING WANG ${ }^{1}$, KAI HU ${ }^{1}$, XIAOYAN KE ${ }^{1}$ and LIN FU ${ }^{1}$ \\ ${ }^{1}$ Department of Hematology and Lymphoma Research Center, Peking University, Third Hospital, Beijing 100191; \\ Departments of ${ }^{2}$ Biomedical Engineering and ${ }^{3}$ Medical Big Data, Chinese People's Liberation Army General Hospital, \\ Beijing 100853; ${ }^{4}$ Department of Hematology, The First Affiliated Hospital of Xinxiang Medical University, \\ Weihui, Henan 453100, P.R. China
}

Received February 15, 2018; Accepted March 20, 2019

DOI: $10.3892 / \mathrm{ol} .2019 .10250$

\begin{abstract}
MicroRNA-500 (miR-500) is a potential prognostic biomarker in a number of different types of cancer, such as prostate cancer and hepatocellular carcinoma. This study aimed to explore the clinical implications of miR-500 expression status in patients with acute myeloid leukemia (AML) that had received allogeneic hematopoietic stem cell transplantation (allo-HSCT). miR-500 expression status and clinical data were obtained from 74 patients with AML in the The Cancer Genome Atlas database receiving allo-HSCT. Patients with low expression level of miR-500 (miR-500 low $)$ were significantly more likely to present with a French-American-British classification M2 subtype $(\mathrm{P}=0.003)$, and less likely to have the M5 subtype $(\mathrm{P}=0.040)$ compared with patients with high expression levels (miR-500 ${ }_{\text {high }}$ ). miR-500 low patients were associated with low-risk AML $(\mathrm{P}=0.003)$ and core-binding factor subunit $\mathrm{b}$-myosin heavy chain 11 translocation mutation $(\mathrm{P}=0.021)$. There was a significant difference in nucleophosmin $1(\mathrm{P}=0.009)$, NRAS proto-oncogene GTPase/KRAS proto-oncogene GTPase $(\mathrm{P}=0.047)$ and $\mathrm{PHD}$ finger protein $6(\mathrm{P}=0.040)$ expression levels between the two groups. miR-500 $0_{\text {high }}$ patients had a decreased overall survival (OS) time compared with the low expression group $(\mathrm{P}=0.035)$. Multivariate analysis revealed that miR-500 expression significantly affected OS time independent of other classical prognostic factors, such as age and common mutations. The analysis of survival curves further substantiated this
\end{abstract}

Correspondence to: Professor Xiaoyan Ke or Professor Lin Fu, Department of Hematology and Lymphoma Research Center, Peking University, Third Hospital, 49 Huayuan North Road, Beijing 100191, P.R. China

E-mail: xykbysy@163.com

E-mail: fulin022@126.com

Key words: microRNA-500, acute myeloid leukemia, allogeneic hematopoietic stem cell transplantation, prognosis result. The results obtained in the current study suggested that miR-500 may be a suitable prognostic marker for patients with AML receiving allo-HSCT.

\section{Introduction}

Acute myeloid leukemia (AML) is characterized by the infiltration of bone marrow and peripheral blood by proliferative, clonal, abnormally differentiated cells of the hematopoietic system (1).

A number of biomarkers are currently used for the diagnosis, prognosis evaluation and treatment strategy of patients with AML, including karyotype, molecular classifications and mutation analysis (2). Classically, specific recurrent chromosomal translocations, including inversion(16) [inv(16)], translocation $(8 ; 21)[\mathrm{t}(8 ; 21)]$ and $\mathrm{t}(15 ; 17)$ indicate a positive prognosis, while chromosomal deletions (dels) including del(5q), -5 and -7 are associated with more severe disease phenotypes. Gene mutations in fms-related tyrosine kinase 3 (FLT3), DNA methyltransferase $3 \alpha$ (DNMT3A), KIT proto-oncogene, receptor tyrosine kinase (KIT), runt-related transcription factor 1 (RUNX1), isocitrate dehydrogenase $(\mathrm{NADP}(+)) 1$ cytosolic and isocitrate dehydrogenase (NADP $(+)) 2$ mitochondrial indicate a poor outcome, while mutations in nucleophosmin 1 (NPM1) and CCAAT enhancer binding protein a are associated with a favorable prognosis $(3,4)$. With advances in molecular biology, the understanding of the molecular causes for AML is gradually increasing. Therefore, an increased number prognostic factors and therapeutic targets, including epigenetic markers, have become topics of investigation.

MicroRNAs (miRNAs/miRs) are a class of short non-coding RNA molecules 22 nucleotides in length which regulate gene expression at the post-transcriptional level (5). miRNAs bind to the 3'-untranslated region of specific target mRNAs, and may affect cell proliferation, differentiation, apoptosis and tumorigenesis (6). In the hematopoietic system, the expression of miRNAs and the related processing proteins is important for the maintenance of hematopoietic stem cells (7). Additionally, the dysregulation of miRNAs has been linked to the progression of hematopoietic malignancies, providing new avenues 
for anticancer research. One of the first studies in this line of research investigated the effect of miR-15a and miR-16-1 in chronic lymphocytic leukemia (8).

miR-500 was first reported as a cancer-associated miRNA in hepatocellular carcinoma (9). Subsequent studies have suggested that miR-500 is involved in the development and progression of a number of solid tumors, including prostate (10) and gastric cancer (11). Although several prognostic factors have been identified for AML, there are only limited indicators for assessing the likely outcomes for patients undergoing allogeneic hematopoietic stem cell transplantation (allo-HSCT). Thus, the aim of the present study was to investigate and analyze the clinical significance of miR-500 in patients with AML receiving allo-HSCT.

\section{Patients and methods}

Patients. The genomic and clinical data of 74 patients with AML were downloaded from The Cancer Genome Atlas database (TCGA; cancergenome.nih.gov). The diagnosis and classification of the patients were based on the World Health Organization and the French-America-British classification systems $(12,13)$. The clinical data included age, sex and white blood cell (WBC) count. The mutation status of commonly mutated genes, as determined by next-generation sequencing, karyotypes and data regarding overall survival (OS) time were available.

All patients provided signed written informed consent in the original study (12), which was approved by the Human Research Ethics Committee of Washington University.

Statistical analysis. To explore the clinical relevance of the miR-500 expression level in patients with AML receiving allo-HSCT, the patients were divided into high and low miR-500 expression groups (miR-500 $0_{\text {high }}$ and miR-500 low, respectively) based on the median expression value, which was determined to be 8.766 (range, 0.545-72.375). Continuous data are presented as medians with ranges. The Mann-Whitney $\mathrm{U}$ and chi-square tests were used to evaluate continuous and categorical variables, respectively. A Cox proportional hazards model was performed to assess the effect of miR-500 expression on OS time. Survival curves were plotted using the Kaplan-Meier method to analyze the relationship between the miR-500 expression level and OS. The log-rank test was used to evaluate the differences between survival distributions. OS was defined as the time from the date of diagnosis until the date of mortality from any cause. The statistical analyses in the study were performed with SPSS (version 20; IBM Corporation, Armonk, NY, USA) and GraphPad Prism (version 6; GraphPad Software, Inc., La Jolla, CA, USA). P<0.05 was considered to indicate a statistically significant difference.

\section{Results}

Demographic and biological characteristics associated with miR-500 expression level. Data regarding 74 patients with AML undergoing allo-HSCT, including 42 males and 32 females, were extracted from the TCGA database. The relevant biological and clinical characteristics of the patients are presented in Table I. There was no significant association between miR-500 expression level and age, sex, WBC count, bone marrow blasts, peripheral blood blast proportion or karyotype. There were significantly more M2 subtype patients in the miR-500 $0_{\text {low }}$ group compared with the miR-500 $0_{\text {high }}$ group $(\mathrm{P}=0.003)$, while all M5 subtype patients were in the miR-500 $0_{\text {high }}$ group $(\mathrm{P}=0.040)$. The cytogenetic classification revealed that the $\mathrm{miR}-500_{\text {low }}$ group was enriched in patients with inv(16)/core-binding factor subunit b (CBFB)-myosin heavy chain 11 (MYH11) $(\mathrm{P}=0.021)$. The miR-500 $0_{\text {low }}$ group was associated with a favorable molecular risk stratification, and all patients with a good molecular prognosis were in the miR-500 low group $(\mathrm{P}=0.003)$. Among the common gene mutations with prognostic significance in AML with a frequency of at least $5 \%$, significant differences were observed in the frequency of NPM1 $(\mathrm{P}=0.009), \mathrm{NRAS} / \mathrm{KRAS}$ $(\mathrm{P}=0.047)$ and $\mathrm{PHD}$ finger protein $6(\mathrm{PHF} 6 \mathrm{P}=0.040)$ mutations between the two groups. NPM1 mutation appeared more frequently in the miR-500 low group, and the miR-500 ${ }_{\text {high }}$ group was associated with NRAS/KRAS and PHF6 mutations. However, the relapse rate and the sources of hematopoietic stem cells were not significantly associated with miR-500 level.

Univariate and multivariate analysis for OS. In order to investigate the prognostic significance of demographic and biological characteristics, survival analysis was performed based on the expression status of miR-500 (high vs. low), age ( $<60$ vs. $\geq 60$ years), WBC count $\left(<30 \times 10^{9}\right.$ vs. $\left.>30 \times 10^{9} / 1\right)$ and common gene mutations [FLT3, NPM1, DNMT3A, WT1 transcription factor, RUNX1, tumor protein (TP53), PHF6, lysine methyltransferase 2A (KMT2A) and NRAS/KRAS; mutated vs. wild type].

A Cox proportional hazards univariate analysis indicated that patients with high miR-500 expression had a shorter OS time compared with patients with low expression $(\mathrm{P}=0.035)$. Mutations in PHF6, KMT2A, RUNX1 and TP53 significantly affected the OS time compared with wild-type genes (all $\mathrm{P}<0.05$; Table II). Multivariate Cox regression analyses were subsequently performed to determine the association of miR-500 expression level and classical clinical and molecular prognostic factors in AML (Table III). The results revealed miR-500 was independently associated with a poor prognosis, as determined by a decreased OS time $(\mathrm{P}=0.008)$, while classical biomarkers including mutations in the genes FLT3, NPM1 and DNMT3A had no independent association with OS time.

Survival curves for the two miR-500 expression groups. Survival curves plotted with the Kaplan-Meier method revealed that the high expression of miR-500 was associated with a shorter OS time ( $\mathrm{P}=0.033$; Fig. 1$)$.

\section{Discussion}

The present study revealed that high expression of miR-500 may be associated with a shorter OS time in patients with AML undergoing allo-HSCT compared with low expression. When considered with other known prognostic factors assessed by the multivariate analysis, $\mathrm{miR}-500$ had an independent prognostic value.

A previous study suggested that determining the mutation status of NPM1 following allo-HSCT may predict the likelihood of relapse (14). While it was previously reported that FLT3 mutation status does not adversely impact OS time following allo-HSCT (15), another study revealed that 
Table I. Comparison of the clinical and molecular characteristics of patients with AML stratified according to the expression of miR-500.

\begin{tabular}{|c|c|c|c|c|}
\hline Characteristics & $\operatorname{miR}-500_{\text {low }}(n=37)$ & $\operatorname{miR}-500_{\text {high }}(\mathrm{n}=37)$ & Statistics & P-value \\
\hline Median age (range), years & $49(22-72)$ & $53(18-65)$ & $\mathrm{U}=654.0$ & 0.741 \\
\hline \multicolumn{3}{|l|}{ Age group, n (\%) } & \multirow[t]{3}{*}{$\chi^{2}=1.096$} & \multirow[t]{3}{*}{0.295} \\
\hline$<60$ years & $29(78.4)$ & $25(67.6)$ & & \\
\hline$\geq 60$ years & $8(21.6)$ & $12(32.4)$ & & \\
\hline \multicolumn{3}{|l|}{ Sex, n $(\%)$} & \multirow[t]{3}{*}{$\chi^{2}=0.881$} & \multirow[t]{3}{*}{0.348} \\
\hline Male & $19(51.4)$ & $23(62.2)$ & & \\
\hline Female & $18(48.6)$ & $14(37.8)$ & & \\
\hline Median white blood cell count (range), $\times 10^{9} / 1$ & $30.9(0.6-202.7)$ & $27.1(0.8-233.8)$ & $\mathrm{U}=742.5$ & 0.531 \\
\hline IMedian bone marrow blasts (range), \% & $67(34-100)$ & $75(30-97)$ & $\mathrm{U}=592.0$ & 0.317 \\
\hline Median peripheral blood blasts (range), $\%$ & $48(0-96)$ & $45(0-90)$ & $\mathrm{U}=791.6$ & 0.166 \\
\hline \multicolumn{3}{|l|}{ French-American-British subtype, n (\%) } & \multirow[t]{9}{*}{$\chi^{2}=17.709$} & 0.024 \\
\hline M0 & $5(13.5)$ & $4(10.8)$ & & 0.722 \\
\hline M1 & $9(24.3)$ & $14(37.8)$ & & 0.209 \\
\hline M2 & $15(40.5)$ & $4(10.8)$ & & 0.003 \\
\hline M3 & $2(5.4)$ & $0(0.0)$ & & 0.152 \\
\hline M4 & $5(13.5)$ & $9(24.3)$ & & 0.235 \\
\hline M5 & $0(0.0)$ & $4(10.8)$ & & 0.040 \\
\hline M6 & $0(0.0)$ & $1(2.7)$ & & 0.314 \\
\hline M7 & $0(0.0)$ & $1(2.7)$ & & 0.314 \\
\hline \multicolumn{3}{|l|}{ Karyotype, n (\%) } & \multirow[t]{14}{*}{$\chi^{2}=16.216$} & 0.063 \\
\hline Normal & $13(35.1)$ & $21(56.8)$ & & 0.062 \\
\hline Complex & $5(13.5)$ & 7 (18.9) & & 0.528 \\
\hline 8 Trisomy & $3(8.1)$ & $3(8.1)$ & & 1.000 \\
\hline $\operatorname{inv}(16) /$ core-binding factor subunit & $5(13.5)$ & $0(0.0)$ & & 0.021 \\
\hline \multicolumn{4}{|l|}{$\beta$-myosin heavy chain 11} & \\
\hline $11 \mathrm{q} 23 /$ lysine methyltransferase $2 \mathrm{~A}$ & $0(0.0)$ & $3(8.1)$ & & 0.077 \\
\hline$-7 / 7 q-$ & $2(5.4)$ & $1(2.7)$ & & 0.556 \\
\hline $\begin{array}{l}\mathrm{t}(15 ; 17) / \text { promyelocytic leukemia-retinoic } \\
\text { acid receptor } \alpha\end{array}$ & $2(5.4)$ & $0(0.0)$ & & 0.152 \\
\hline $\mathrm{t}(9 ; 22) / \mathrm{BCR}$ activator of RhoGEF and & $1(2.7)$ & $1(2.7)$ & & 1.000 \\
\hline \multicolumn{4}{|l|}{$\begin{array}{l}\text { GTPase-ABL proto-oncogene } 1 \text {, non-receptor } \\
\text { tyrosine kinase }\end{array}$} & \\
\hline $\mathrm{t}(8 ; 21) /$ runt-related transcription factor & $1(2.7)$ & $0(0.0)$ & & 0.314 \\
\hline \multicolumn{4}{|l|}{ 1- RUNX1 translocation partner 1} & \\
\hline Other/undefined subtypes & $5(13.5)$ & $1(2.7)$ & & 0.088 \\
\hline \multicolumn{3}{|l|}{ Molecular risk stratification, $\mathrm{n}(\%)$} & \multirow[t]{4}{*}{$\chi^{2}=9.776$} & 0.021 \\
\hline Good & $8(21.6)$ & $0(0.0)$ & & 0.003 \\
\hline Intermediate & $18(48.6)$ & $23(62.2)$ & & 0.242 \\
\hline Poor & $11(29.7)$ & $13(35.1)$ & & 0.619 \\
\hline \multicolumn{3}{|l|}{ Fms-related tyrosine kinase $3, \mathrm{n}(\%)$} & \multirow[t]{3}{*}{$\chi^{2}=1.909$} & \multirow[t]{3}{*}{0.167} \\
\hline Mutation & $6(16.2)$ & $11(29.7)$ & & \\
\hline Wild-type & $31(83.8)$ & $26(70.3)$ & & \\
\hline \multicolumn{3}{|l|}{ Nucleophosmin $1, \mathrm{n}(\%)$} & \multirow[t]{3}{*}{$\chi^{2}=6.852$} & \multirow[t]{3}{*}{0.009} \\
\hline Mutation & $5(13.5)$ & $15(40.5)$ & & \\
\hline Wild-type & $32(86.5)$ & $22(59.5)$ & & \\
\hline \multicolumn{3}{|l|}{ CCAAT enhancer binding protein $\alpha, \mathrm{n}(\%)$} & \multirow[t]{4}{*}{$\chi^{2}=5.345$} & 0.069 \\
\hline Single mutation & $4(10.8)$ & $1(2.7)$ & & \\
\hline Double mutation & $3(8.1)$ & $0(0.0)$ & & \\
\hline Wild-type & $30(81.1)$ & $36(97.3)$ & & \\
\hline
\end{tabular}


Table I. Continued.

\begin{tabular}{|c|c|c|c|c|}
\hline Characteristics & miR-500 ${ }_{\text {low }}(\mathrm{n}=37)$ & $\operatorname{miR}-500_{\text {high }}(\mathrm{n}=37)$ & Statistics & P-value \\
\hline DNA methyltransferase $3 \alpha, \mathrm{n}(\%)$ & & & $\chi^{2}=0.294$ & 0.588 \\
\hline Mutation & $10(27.0)$ & $8(21.6)$ & & \\
\hline Wild-type & $27(73.0)$ & $29(78.4)$ & & \\
\hline Isocitrate dehydrogenase (NADP $(+))$ & & & $\chi=0.107$ & 0.744 \\
\hline \multicolumn{5}{|l|}{1 , cytosolic, $\mathrm{n}(\%)$} \\
\hline Mutation & $5(13.5)$ & $6(16.2)$ & & \\
\hline Wild-type & $32(86.5)$ & $31(83.8)$ & & \\
\hline Isocitrate dehydrogenase, $\mathrm{n}(\%)[\mathrm{NADP}(+)]$ & & & $\chi^{2}=0.561$ & 0.454 \\
\hline \multicolumn{5}{|l|}{ 2, mitochondrial } \\
\hline Mutation & $3(8.1)$ & $5(13.5)$ & & \\
\hline Wild-type & $34(91.9)$ & $32(86.5)$ & & \\
\hline WT1 transcription factor, $\mathrm{n}(\%)$ & & & $\chi^{2}=0.126$ & 0.722 \\
\hline Mutation & $5(13.5)$ & $4(10.8)$ & & \\
\hline Wild-type & $32(86.5)$ & $33(89.2)$ & & \\
\hline Runt-related transcription factor $1, \mathrm{n}(\%)$ & & & $\chi^{2}=2.242$ & 0.134 \\
\hline Mutation & $2(5.4)$ & $6(16.2)$ & & \\
\hline Wild-type & $35(94.6)$ & $31(83.8)$ & & \\
\hline Lysine methyltransferase $2 \mathrm{~A}, \mathrm{n}(\%)$ & & & $\chi^{2}=1.507$ & 0.304 \\
\hline Mutation & $1(2.7)$ & $3(8.1)$ & & \\
\hline Wild-type & $36(97.3)$ & $34(91.9)$ & & \\
\hline NRAS/KRAS proto-oncogene GTPase, n (\%) & & & $\chi^{2}=3.945$ & 0.047 \\
\hline Mutation & $6(16.2)$ & $1(2.7)$ & & \\
\hline Wild-type & $31(83.8)$ & $36(97.3)$ & & \\
\hline Tet methylcytosine dioxygenase $2, \mathrm{n}(\%)$ & & & $\chi^{2}=1.057$ & 0.304 \\
\hline Mutation & $3(8.1)$ & $1(2.7)$ & & \\
\hline Wild-type & $34(91.9)$ & $36(97.3)$ & & \\
\hline Tumor protein $53, \mathrm{n}(\%)$ & & & $\chi^{2}=1.057$ & 0.304 \\
\hline Mutation & $1(2.7)$ & $3(8.1)$ & & \\
\hline Wild-type & $36(97.3)$ & $34(91.9)$ & & \\
\hline KIT proto-oncogene, receptor tyrosine & & & $\chi^{2}=1.057$ & 0.304 \\
\hline kinase, $\mathrm{n}(\%)$ & & & & \\
\hline Mutation & $3(8.1)$ & $1(2.7)$ & & \\
\hline Wild-type & $34(91.9)$ & $36(97.3)$ & & \\
\hline $\begin{array}{l}\text { Protein tyrosine phosphatase non-receptor } \\
\text { type } 11, \mathrm{n}(\%)\end{array}$ & & & $\chi^{2}=1.930$ & 0.165 \\
\hline Mutation & $1(2.7)$ & $4(10.8)$ & & \\
\hline Wild-type & $36(97.3)$ & $33(89.2)$ & & \\
\hline PHD finger protein $6, \mathrm{n}(\%)$ & & & & \\
\hline Mutation & $0(0.0)$ & $4(10.8)$ & $\chi^{2}=4.229$ & 0.040 \\
\hline Wild-type & $37(100.0)$ & $33(89.2)$ & & \\
\hline Relapse, n (\%) & & & $\chi^{2}=0.063$ & 0.802 \\
\hline Yes & $26(70.3)$ & $25(67.6)$ & & \\
\hline No & $11(29.7)$ & $12(32.4)$ & & \\
\hline $\begin{array}{l}\text { Source of hematopoietic stem, n (\%) } \\
\text { cell transplantation }\end{array}$ & & & $\chi^{2}=4.900$ & 0.086 \\
\hline Haplogeneic & $2(5.4)$ & $0(0.0)$ & & \\
\hline Sib allogeneic & $12(32.4)$ & $20(54.1)$ & & \\
\hline Matched unrelated donor & $23(62.2)$ & $17(45.9)$ & & \\
\hline
\end{tabular}

U, Mann-Whitney U; t, translocation; sib, matched sibling. 
Table II. Univariate analysis of OS.

OS

Variables

Hazard ratio (95\% confidence interval)

P-value

MicroRNA-500 (high vs. low)

$0.563(0.330-0.961)$

0.035

Age ( $<60$ vs. $\geq 60$ years)

$1.448(0.807-2.599)$

0.215

White blood cell count ( $<30$ vs. $\geq 30 \times 10^{9} / 1$ )

$0.996(0.585-1.694)$

0.988

Fms-related tyrosine kinase 3 mutation

$0.624(0.333-1.170)$

0.141

Nucleophosmin 1 mutation

$1.099(0.598-2.019)$

0.761

DNA methyltransferase 3 mutation

$0.757(0.410-1.398)$

0.374

WT1 transcription factor mutation

$0.590(0.276-1.262)$

0.174

Runt-related transcription factor 1 mutation

$0.431(0.201-0.927)$

0.031

Tumor protein 53 mutation

$0.255(0.087-0.750)$

0.013

PHD finger protein 6 mutation

$0.321(0.114-0.906)$

0.032

Lysine methyltransferase 2A mutation

$0.309(0.110-0.869)$

0.026

OS, overall survival.

Table III. Multivariate analysis of OS.

OS

Variable

Hazard ratio (95\% confidence interval)

P-value

MicroRNA-500 (high vs. low)

$0.440(0.241-0.803)$

0.008

Age ( $<60$ vs. $\geq 60$ years)

White blood cell count ( $<30$ vs. $\left.\geq 30 \times 10^{9} / 1\right)$

$1.448(0.777-2.697)$

0.244

$1.093(0.615-1.943)$

0.762

Fms-related tyrosine kinase 3 mutation

$0.612(0.288-1.302)$

0.203

Nucleophosmin 1 mutation

$2.315(0.990-5.415)$

0.053

DNA methyltransferase $3 \alpha$ mutation

$0.643(0.339-1.220)$

0.177

OS, overall survival.

FLT3 and DNMT3A R882 mutations were associated with poor prognosis in patients with AML receiving allo-HSCT treatment (16). The results of the current study suggested that miR-500 had an adverse effect on OS time, while mutations in the genes FLT3, NPM1 and DNMT3A were not independently associated with OS time in patents with AML receiving allo-HSCT. Thus, the results indicated that while allo-HSCT is an effective treatment strategy that may overcome the adverse effect of classical mutations, miR-500 is a more effective indicator of prognosis in patients with AML receiving allo-HSCT compared with the aforementioned mutations.

The subgroup of patients with AML with inv(16)/CBBBMYH11, one of the most common cytogenetic aberrations in AML, tend to have an improved prognosis compared with patients without this aberration (17). This was also observed for patients with a low expression level of miR-500 in the present study. The lower expression of miR-500 was associated with a higher proportion of patients with inv(16), which may be associated with an improved prognosis. As presented in Table I, all the patients with a favorable molecular risk were in the miR-500 group in the current study, suggesting that miR-500 expression

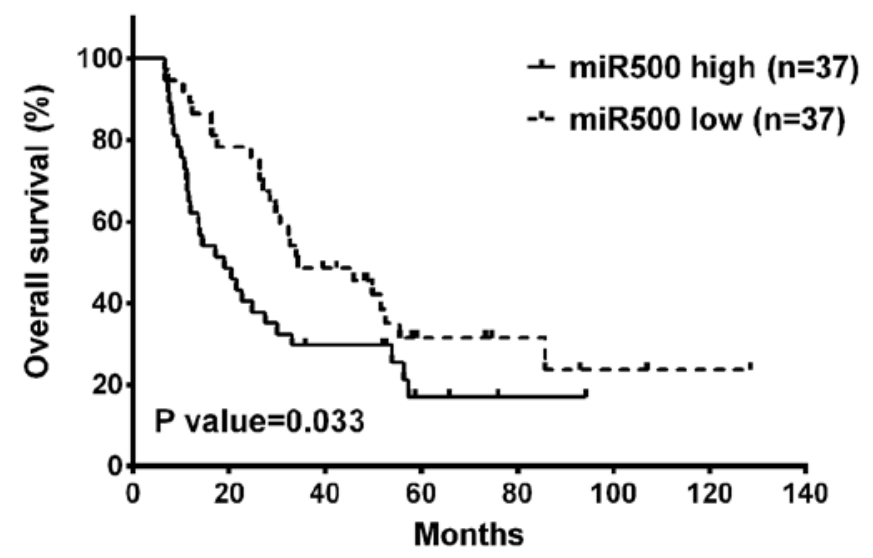

Figure 1. Kaplan-Meier curves for overall survival time. Patients in the high miR-500 expression group had a significantly decreased overall survival time compared with those in the low expression group.

adversely affects the prognosis of patients with AML receiving allo-HSCT. Mutations in the tumor suppressor gene PHF6 may be encountered in patients with AML (18), therefore a PHF6 
mutation and high miR-500 expression may result in a poor prognosis. Although NPM1 mutation is a favorable factor in AML, patients with high expression of miR-500 and NPM1 mutation were associated with a poor prognosis in the present study.

miR-500 is located on the $\mathrm{X}$ chromosome. A previous study has demonstrated that miR-500 may be involved in cell proliferation and apoptosis (10). It may activate the nuclear factor (NF)- $\kappa b$ signaling pathway and suppress NF- $\kappa b$ negative regulatory genes. miR-500 may serve a role in tumorigenesis by sustaining NF- $\mathrm{kb}$ activation and disrupting ubiquitin deconjugation (11). Cai et al (10) demonstrated that miRNA-500 acts on the downstream target tissue factor pathway inhibitor, and may affect the outcome in human prostate cancer.

Due to the limited number of cases included in the present study, the results obtained have relatively low power. Further analysis with a larger cohort is warranted to validate the prognostic value of miR-500 in patients with AML receiving allo-HSCT. Furthermore, to the best of our knowledge, the miR-500 expression level in patients AML has not been previously investigated and the role of miR-500 in the development of hematological malignancies requires further experimentation in vitro and in vivo.

In conclusion, the results obtained in the current study indicated that miR-500 may be a potential prognostic biomarker for patients with AML undergoing allo-HSCT.

\section{Acknowledgements}

Not applicable.

\section{Funding}

The present study was supported by grants from the National Natural Science Foundation of China (grant nos. 81500118 and 61501519), the China Postdoctoral Science Foundation Project Fund (grant no. 2016M600443) and the PLAGH project of Medical Big Data (grant no. 2016MBD-025).

\section{Availability of data and materials}

All the data in this study were derived from The Cancer Genome Atlas (TCGA) database.

\section{Authors' contributions}

$\mathrm{XK}$ and LF designed and refined the study, GZ wrote the manuscript, JS analyzed the data, and GZ, XY, XZ, JZ, SY, $\mathrm{LZ}, \mathrm{KH}$ and JW performed the statistical analyses. XK and LF supervised the study throughout. All authors read and approved the final manuscript.

\section{Ethics approval and consent to participate}

The study was approved by the Human Research Ethics Committee of Washington University. All patients provided written informed consent.

\section{Patient consent for publication}

Not applicable.

\section{Competing interests}

The authors declare that they have no competing interests.

\section{References}

1. Cazzola M, Della Porta MG, Travaglino E and Malcovati L: Classification and prognostic evaluation of myelodysplastic syndromes. Semin Oncol 38: 627-634, 2011.

2. Wang YX, Zhang TJ, Yang DQ, Yao DM, Yang L, Zhou JD, Deng ZQ, Ma JC, Guo H, Wen XM, et al: Reduced miR-215 expression predicts poor prognosis in patients with acute myeloid leukemia. Jpn J Clin Oncol 46: 350-356, 2016.

3. Döhner H, Weisdorf DJ and Bloomfield CD: Acute myeloid leukemia. N Engl J Med 373: 1136-1152, 2015.

4. Marcucci G, Haferlach T and Dohner H: Molecular genetics of adult acute myeloid leukemia: Prognostic and therapeutic implications. J Clin Oncol 29: 475-486, 2011.

5. Agirre X, Martínez-Climent JÁ, Odero MD and Prósper F: Epigenetic regulation of miRNA genes in acute leukemia. Leukemia 26: 395-403, 2012.

6. Zhang R and Su B: Small but influential: The role of microRNAs on gene regulatory network and $3^{\prime}$ UTR evolution. J Genet Genomics 36: 1-6, 2009.

7. Palma CA, Tonna EJ, Ma DF and Lutherborrow MA: MicroRNA control of myelopoiesis and the differentiation block in acute myeloid leukaemia. J Cell Mol Med 16: 978-987, 2012.

8. Calin GA, Dumitru CD, Shimizu M, Bichi R, Zupo S, Noch E, Aldler H, Rattan S, Keating M, Rai K, et al: Frequent deletions and down-regulation of micro- RNA genes miR15 and miR16 at 13q14 in chronic lymphocytic leukemia. Proc Natl Acad Sci USA 99: 15524-15529, 2002.

9. Yamamoto Y, Kosaka N, Tanaka M, Koizumi F, Kanai Y, Mizutani T, Murakami Y, Kuroda M, Miyajima A, Kato T and Ochiya T: MicroRNA-500 as a potential diagnostic marker for hepatocellular carcinoma. Biomarkers 14: 529-538, 2009.

10. Cai B, Chen W, Pan Y, Chen H, Zhang Y, Weng Z and Li Y: Inhibition of microRNA-500 has anti-cancer effect through its conditional downstream target of TFPI in human prostate cancer. Prostate 77: 1057-1065, 2017.

11. Zhang L, Ding Y, Yuan Z, Liu J, Sun J, Lei F, Wu S, Li S and Zhang D: MicroRNA-500 sustains nuclear factor- $\kappa$ B activation and induces gastric cancer cell proliferation and resistance to apoptosis. Oncotarget 6: 2483-2495, 2015.

12. Cancer Genome Atlas Research Network, Ley TJ, Miller C, Ding L, Raphael BJ, Mungall AJ, Robertson A, Hoadley K, Triche TJ Jr, Laird PW, et al: Genomic and epigenomic landscapes of adult de novo acute myeloid leukemia. N Engl J Med 368: 2059-2074, 2013.

13. Mrózek K, Marcucci G, Nicolet D, Maharry KS, Becker H, Whitman SP, Metzeler KH, Schwind S, Wu YZ, Kohlschmidt J, et al: Prognostic significance of the European LeukemiaNet standardized system for reporting cytogenetic and molecular alterations in adults with acute myeloid leukemia. J Clin Oncol 30: 4515-4523, 2012.

14. Xue E, Tresoldi C, Sala E, Crippa A, Mazzi B, Greco R, Messina C, Carrabba MG, Lupo Stanghellini MT, Marktel S, et al: Longitudinal qPCR monitoring of nucleophosmin 1 mutations after allogeneic hematopoietic stem cell transplantation to predict AML relapse. Bone Marrow Transplant 51: 466-469, 2016.

15. Deol A, Sengsayadeth S, Ahn KW, Wang HL, Aljurf M, Antin JH, Battiwalla M, Bornhauser M, Cahn JY, Camitta B, et al: Does FLT3 mutation impact survival after hematopoietic stem cell transplantation for acute myeloid leukemia? A Center for International Blood and Marrow Transplant Research (CIBMTR) analysis. Cancer 122: 3005-3014, 2016.

16. Tang S, Shen H, Mao X, Dai H, Zhu X, Xue S, Ding Z, Lu J, Wu D and Tang X: FLT3-ITD with DNMT3A R882 double mutation is a poor prognostic factor in Chinese patients with acute myeloid leukemia after chemotherapy or allogeneic hematopoietic stem cell transplantation. Int J Hematol 106: 552-561, 2017.

17. Chan NP, Wong WS, Ng MH, Tsang KS, Lau TT, Leung Y, Chik KW, Shing MM and Li CK: Childhood acute myeloid leukemia with CBFbeta-MYH11 rearrangement: Study of incidence, morphology, cytogenetics, and clinical outcomes of Chinese in Hong Kong. Am J Hematol 76: 300-303, 2004.

18. Van Vlierberghe P, Patel J, Abdel-Wahab O, Lobry C, Hedvat CV, Balbin M, Nicolas C, Payer AR, Fernandez HF, Tallman MS, et al: PHF6 mutations in adult acute myeloid leukemia. Leukemia 25: 130-134, 2011. 